\title{
Is it about time to forget about intravascular lead?
}

Takashi Nitta, MD, PhD

\author{
From the Department of Cardiovascular Surgery, Nippon Medical School, Tokyo, Japan. \\ Disclosures: Author has nothing to disclose with regard to commercial support. \\ Received for publication Dec 11, 2017; accepted for publication Dec 20, 2017; available ahead of print Jan 19, \\ 2018. \\ Address for reprints: Takashi Nitta, MD, PhD, Department of Cardiovascular Surgery, Nippon Medical School, \\ 1-1-5 Sendagi, Bunkyo-ku, Bunkyo-ku, Tokyo 113-8603, Japan (E-mail: nitta@nms.ac.jp). \\ J Thorac Cardiovasc Surg 2018;155:1509-10 \\ $0022-5223 / \$ 36.00$ \\ Copyright (c) 2018 by The American Association for Thoracic Surgery \\ https://doi.org/10.1016/j.jtcvs.2017.12.103
}

Tricuspid regurgitation (TR) is frequently seen in patients with endocardial leads of permanent pacemakers (PPMs). Saran and colleagues ${ }^{1}$ of the Mayo Clinic examined the outcome of tricuspid valve surgery in patients with PPMs. They classified the patients into 2 groups, PPM-associated TR and PPM-induced TR, on the basis of the intraoperative findings of the tricuspid valve. Congestive heart failure was more common in the patients with PPM-associated TR and the mechanism of TR was usually functional, whereas a variety of mechanical effects of endocardial leads on the valve leaflet led to valve incompetence in the patients with PPM-induced TR. The patients with PPM-induced TR showed better prognosis with improved survival than patients with PPM-associated TR. Of note, the patients who underwent tricuspid valve repair for PPM-associated or PPMinduced TR demonstrated better survival than those with valve replacement. TR in the patients with permanent PPMs might have been undervalued despite its high incidence. This article ${ }^{1}$ provides important information on the mechanism of TR and the surgical treatment of this difficult and frequently occurring complication of PPMs.

Intravascular extraction of endocardial leads has become available with the aid of laser or other energies to dissect adhesion between the leads and veins, along with the use of locking devices to deliver dragging force to the entire length of the endocardial leads. ${ }^{2,3}$ There was concern about TR developing as a consequence of lead extraction ${ }^{4}$; however, a recent study using transesophageal echocardiography during the procedure failed to show a significant worsening of TR by lead extraction. ${ }^{5}$ In fact, intravascular lead extraction has been performed to treat PPM-induced TR. ${ }^{6}$ Surgeons can now design the therapeutic strategy by combining tricuspid valve repair with intraoperative antegrade or retrograde application of laser when lead extraction is indicated.

A leadless PPM was recently developed and has come into clinical use. ${ }^{7}$ The incidence of lead-induced TR should be naturally low in the patients with a leadless PPM. Widespread use of the leadless PPM will decrease the incidence of PPM-induced TR. Intravenous PPM leads causing TR are extracted by intravascular extraction with

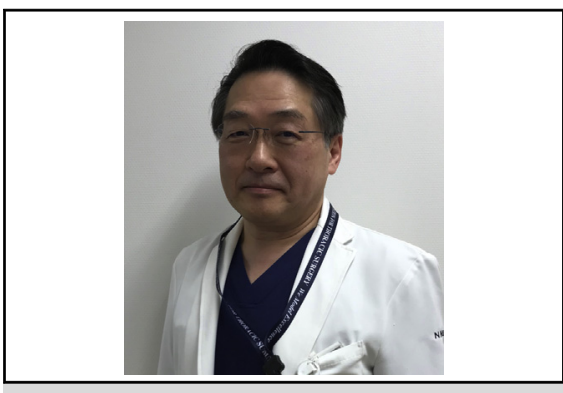

Takashi Nitta, MD, PhD

Central Message

Intravascular lead extraction, leadless pacemaker, and tricuspid clip are now applied to simple types of pacemaker-induced TR.

See Article page 1498.

laser technology, and then the PPM system is replaced by a leadless PPM to avoid recurrence of TR.

A variety of intravascular devices have been developed to treat TR. The MitraClip (Abbott, Abbott Park, Ill) is now used as a tricuspid clip to reduce TR. ${ }^{9}$ PPM-associated TR may be best treated by the tricuspid clip. Simple types of PPM-induced TR, such as restricted mobility of the valve leaflets or light adhesion of a PPM lead, may be treated by a combination of intravascular lead extraction, leadless PPM, and tricuspid clip. ${ }^{8}$ Complex types of PPM-induced TR, such as perforation or scarring of leaflets and chordal entrapment, will be treated by surgeons.

\section{References}

1. Saran N, Said SM, Schaff HV, Maltais S, Stulak JM, Greason KL, et al. Outcome of tricuspid valve surgery in the presence of permanent pacemaker. J Thorac Cardiovasc Surg. 2018;155:1498-508.

2. Wilkoff BL, Byrd CL, Love CJ, Hayes DL, Sellers TD, Schaerf R, et al. Pacemaker lead extraction with the laser sheath: results of the pacing lead extraction with the excimer sheath (PLEXES) trial. J Am Coll Cardiol. 1999;33:1671-6.

3. Wazni O, Epstein LM, Carrillo RG, Love C, Adler SW, Riggio DW, et al Lead extraction in the contemporary setting: the LExICon study: an observational retrospective study of consecutive laser lead extractions. J Am Coll Cardiol. 2010; 55:579-86.

4. Roeffel S, Bracke F, Meijer A, Van Gelder B, Van Dantzig JM, Botman CJ, et al. Transesophageal echocardiographic evaluation of tricuspid valve regurgitation during pacemaker and implantable cardioverter defibrillator lead extraction. Pacing Clin Electrophysiol. 2002;25:1583-6.

5. Pecha S, Castro L, Gosau N, Linder M, Vogler J, Willems S, et al. Evaluation of tricuspid valve regurgitation following laser lead extraction. Eur J Cardiothorac Surg. 2017;51:1108-11.

6. Schaller RD, Sadek MM, Luebbert JJ, Ren JF, Marchlinski FE. Transjugular lead fragment extraction to improve tricuspid regurgitation. HeartRhythm Case Rep. 2015;1:95-8.

7. Reynolds D, Duray GZ, Omar R, Soejima K, Neuzil P, Zhang S, et al. A leadless intracardiac transcatheter pacing system. $N$ Engl J Med. 2016;374:533-41. 
8. Tang GH, Kaple R, Cohen M, Dutta T, Undemir C, Ahmad H, et al. First percutaneous Micra leadless pacemaker implantation and tricuspid valve repair with MitraClip NT for lead-associated severe tricuspid regurgitation. EuroIntervention. 2017;12:e1845-8.
9. Nickenig G, Kowalski M, Hausleiter J, Braun D, Schofer J, Yzeiraj E, et al. Transcatheter treatment of severe tricuspid regurgitation with the edge-to-edge MitraClip technique. Circulation. 2017; 135:1802-14. 